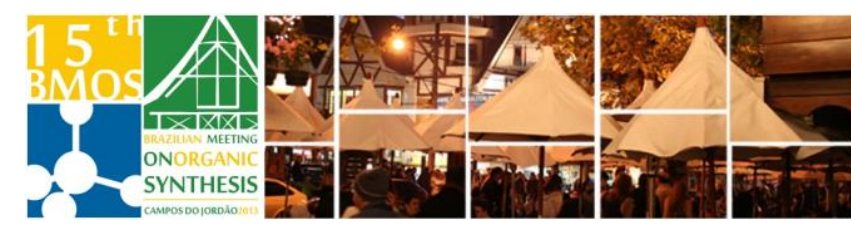

\title{
Iodination of Benzylanilines with Potassium Dichloroiodate
}

\author{
George J. M. Mota (PG) ${ }^{\star}$, Simon J. Garden (PQ) \\ Instituto de Química, Universidade Federal do Rio de Janeiro - Brasil, RJ \\ *gj mota@ufrj.br, garden@iq.ufrj.br
}

Keywords: N-benzylanilines, iodination

\section{INTRODUCTION}

lodinated organic compounds are widely used in organic synthesis as electrophilic agents for crosscoupling reactions that result in carbon-carbon and carbon-heteroatom bond formation. ${ }^{1}$ In this context we are interested in the preparation of orthoiodoaniline derivatives and we have previously made use of an aqueous solution of potassium dichloroiodate $\left(\mathrm{KICl}_{2}\right)$ for the iodination of some (hetero-) aromatic systems. ${ }^{2}$

The iodination of activated aromatic compounds (such as anilines) readily leads to a mixture of mono-, di- or even tri- iodo products. For example the reaction of $p$-toluidine with 1.1 equivalents of $\mathrm{KICl}_{2}$ resulted in the obtention of $20 \%$ substrate, $60 \%$ mono-iodo- and $20 \%$ diiodo- $p$-toluidine. The poor selectivity and a literature precedent for monoiodination of $\mathrm{N}$-alkylanilines ${ }^{3}$ prompted us to investigate the iodination of $N$-benzylanilines.

\section{RESULTS AND DISCUSSION}

$N$-Benzylanilines (4) were prepared by reductive amination of $p$-substituted anilines (1) using $\mathrm{NaBH}_{4}$, Figure 1. Initially, the reaction of $2 \mathrm{~N}$ aqueous $\mathrm{KICl}_{2}$ with $N$-benzyl- $p$-toluidine was studied under various conditions and the respective reactions analyzed by GCMS. Some results are detailed in Table 1.

Table 1. GCMS results (relative \% uncorrected peak areas) for reaction of $N$-benzyl- $p$-toluidine with $\mathrm{KICl}_{2}$.

\begin{tabular}{|l|c|c|c|c|}
\hline$\dagger$ & 1 Sub(\%) & 3 [O]Sub (\%) & 5 Prod (\%) & 6 [O]Prod (\%) \\
\hline$a$ & 17 & 2 & 70 & 11 \\
\hline$b$ & 22 & 12 & 63 & 3 \\
\hline$c$ & $<1$ & $<1$ & 93 & 6 \\
\hline$d$ & $<1$ & $<1$ & 98 & 2 \\
\hline$e$ & $<1$ & $<1$ & 97 & 3 \\
\hline$f$ & $<1$ & $<1$ & 96 & 4 \\
\hline
\end{tabular}

$\dagger$ Conditions [Table entry - solvent, equiv.s NaOAc, equiv.s $\mathrm{KICl}_{2}$, time (mins)]: $a-\mathrm{MeOH}, 0,1.5,140 ; b-$ $\mathrm{MeOH}, \mathrm{AcOH}(4: 1 \mathrm{~V} / \mathrm{V}), 2.5,1.2,100 ; c-\mathrm{MeOH}, \mathrm{AcOH}$, EtOAc $(5: 1: 4 \mathrm{~V} / \mathrm{V} / \mathrm{V}), 3.7,1.5,100 ; d(e, f)=c$, time $=5 \mathrm{~min}$; e $15 \mathrm{~min} ; f 25 \mathrm{~min}$.

The experiments identified a tri-solvent system in the presence of $\mathrm{NaOAc}$ as a potentially effective combination for the rapid mono-iodination of 4 . The methodology was applied to other derivatives of 4 with partial success (Table 2). Oxidative debenzylation of the substrate, or product, was identified as the principle side reaction resulting in some low yields of 5 (Table 2).

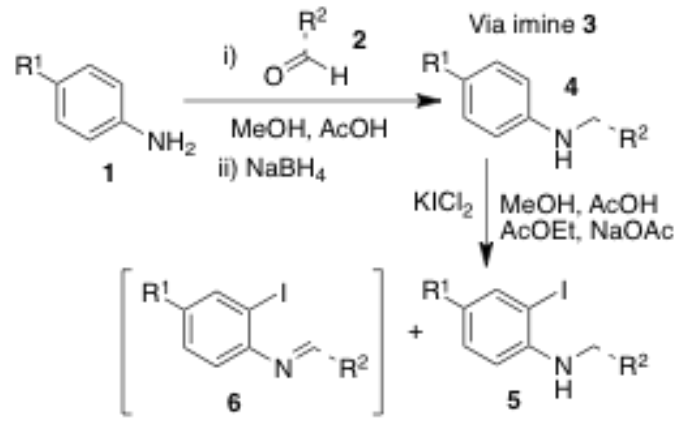

Figure 1. General reaction scheme: reductive amination followed by iodination with aqueous $\mathrm{KICl}_{2}$.

Table 2. Purified product yields for the iodination of $N$ benzylanilines.

\begin{tabular}{|c|c|c|c|c|c|}
\hline $\mathrm{R}^{1}$ & $\mathrm{R}^{2}$ & Yield(\%) & $\mathrm{R}^{1}$ & $\mathrm{R}^{2}$ & Yield(\%) \\
\hline $\mathrm{Br}$ & & 36 & $\mathrm{Br}$ & & 47 \\
\hline $\mathrm{Cl}$ & & 48 & $\mathrm{Cl}$ & \\
\hline $\mathrm{F}$ & & 28 & $\mathrm{Me}$ & & \\
\hline $\mathrm{Me}$ & & 75 & $\mathrm{Cl}$ & \\
\hline
\end{tabular}

\section{CONCLUSION}

The chemoselective iodination of $\mathrm{N}$ benzylanilines is potentially an interesting reaction for the obtention of substrates for application in cross-coupling reactions. The use of aqueous $\mathrm{KICl}_{2}$ in a tri-solvent system has allowed the synthesis of a number of mono-iodinated $\mathrm{N}$-benzylaniline derivatives in moderate to good yields.

\section{ACKNOWLEDGEMENTS}

FAPERJ, CNPq and PGQU-IQ-UFRJ

\section{REFERENCES}

${ }^{1}$ a) Evano, G., Blanchard, N., Toumi, M. Chem. Rev. 2008, 108, 3054. b) Buchwald, S.L. Acc. Chem. Res., 2008, 41, 1439. c) Alberico, D., Scott, M.E., Lautens, M. Chem. Rev. 2007, 107, 174.

${ }^{2}$ Garden, S.J., Torres, J.C., Melo, S.C.S., Lima, A.S., Pinto, A.C., Lima, E.L.S. Tetrahedron Lett. 2001, 42, 2089.

${ }^{3}$ Shen, H. Vollhardt, K.P.C. Synlett, 2012, 23, 208. 